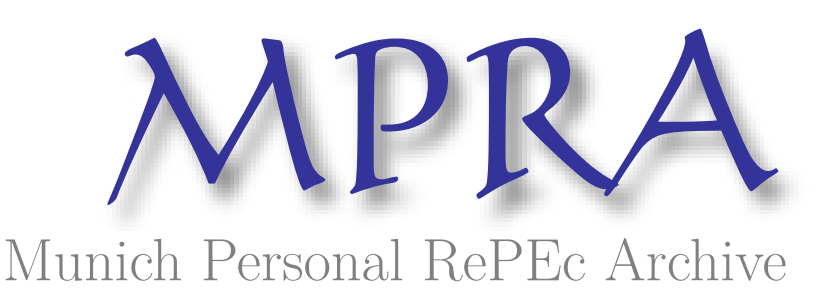

\title{
Breaking the UIP: A Model-Equivalence Result
}

Yakhin, Yossi

Bank of Israel

17 November 2019

Online at https://mpra.ub.uni-muenchen.de/107411/

MPRA Paper No. 107411, posted 26 Apr 2021 13:16 UTC 


\title{
Breaking the UIP: A Model-Equivalence Result*
}

\author{
Yossi Yakhin ${ }^{\dagger}$
}

March 2020

First version: November 2019

\begin{abstract}
Breaking the uncovered interest rate parity (UIP) condition is essential to accounting for the empirical behavior of exchange rates, and is a prerequisite for theoretical analysis of sterilized foreign exchange interventions. Gabaix and Maggiori (2015) account for some of the long-standing empirical exchange rate puzzles by introducing financial intermediaries that are willing to absorb international saving imbalances for a premium, thereby deviating from the UIP. In another important contribution, Fanelli and Straub (2019) lay down the principles for foreign exchange interventions. In their model, regulatory exposure limits and participation cost in the international financial markets drive a wedge in the UIP. This paper demonstrates that, to a first order approximation, these models are equivalent to a reduced-form portfolio adjustment cost model, as in Schmitt-Grohé and Uribe (2003). Therefore, to the extent that one is only concerned with first-order dynamics and second moments, there is no gain from adopting the rich microstructure of either models - a simple portfolio adjustment cost is just as good.
\end{abstract}

JEL classification: E58, F31, F41.

Keywords: UIP, Financial Frictions, Open Economy Macroeconomics.

\footnotetext{
* I thank Jonathan Benchimol, Eliezer Borenstein, Zvi Hercowitz, Alex Ilek, Nimrod Segev and Osnat Zohar for helpful comments and discussion. I also thank seminar participants at the Bank of Israel. All errors are mine. The views expressed in this paper are solely my own and they do not necessarily represent those of the Bank of Israel.

$\dagger$ Research Deapartment, Bank of Israel. Email: Yossi.Yakhin@boi.org.il
} 


\section{Introduction}

Breaking the uncovered interest rate parity (UIP) condition is essential to accounting for the empirical behavior of exchange rates ${ }^{1}$, and it is a prerequisite in theoretical models for the efficacy of sterilized foreign exchange intervention (FXI) through the portfolio balance channel. While the influential work of Backus and Kehoe (1989) points to the inefficacy of sterilized FXIs, recent contributions have revived the argument for their use, e.g. Benes et-al. (2015), Alla et-al. (2017), Cavallino (2019), and Fanelli and Straub (2019). These models introduce financial frictions that differentiate domestic bonds from foreign ones, otherwise, to a first order approximation, the two assets are perfect substitutes, the UIP holds and sterilized FXIs are deemed ineffective.

The contribution of Gabaix and Maggiori (2015), GM hereafter, sketches the microfoundations of a mechanism that introduces a wedge between home and foreign interest rate differential and expected exchange rate movement, thereby deviating from the UIP condition. In their model, international financial markets are segmented and financiers are willing to absorb saving imbalances for a premium, which in turn breaks the UIP. GM forcefully demonstrate that their model can help rationalize some of the long-standing empirical exchange rate puzzles, including the exchange rate disconnect and the forward premium puzzles. In another important contribution, Fanelli and Straub (2019), FS hereafter, lay down the principles for FXIs. The micro-foundations of the financial friction in their model rely on regulatory restrictions that are coupled with financier-specific participation cost in the international financial markets, similar to Alvarez, Atkeson and Kehoe (2009). In FS it is the participation cost of the marginal financier that determines the gap between interest rate differential and the expected change in the exchange rate. Due to the regulatory limits, movements in the foreign asset position of the economy are associated with changes in the identity of the marginal financier, and hence with the marginal participation cost and the size of the deviation from the UIP.

This paper derives an equivalence result: to a first-order approximation the GM and FS models are identical to a standard reduced-form portfolio adjustment cost model, as in

\footnotetext{
1 See Engel (2014) and references therein.
} 
Schmitt-Grohé and Uribe (2003), SGU hereafter. In SGU the purpose of the friction is to impose stationarity in small open economy models. They achieve it by endogenizing the effective foreign return faced by the agents in the small economy, as by assumption these agents bear cost whenever their foreign asset position deviates from some benchmark level. Since in GM and FS, as in SGU, movements in the foreign asset position generate a time-varying wedge between the global risk-free rate and the effective foreign return faced by domestic agents, it is not surprising to find that the UIP conditions in these models are closely related. The simple modeling strategy of SGU is therefore robust to different underlying micro structures. The implication of the equivalence result is that, to the extent that one is only concerned with first-order dynamics and second moments of macro variables - as is typically the case in the open economy business cycle literature and in many new-Keynesian models - there is no gain from adopting the rich micro-structure of either GM or FS; a simple ad-hoc friction as in SGU is just as good. Moreover, the underlying micro foundations of GM and FS do not carry into higher order terms in the UIP condition, suggesting that the simplicity of the first order approximation does not sacrifice important higher order dynamics.

The exposition of the models in this paper is deliberately lean, and they contain the minimal structure needed for discussing deviations from the UIP. The models abstract from production and use one global good, suggesting that the real exchange rate is fixed at unity. The nominal exchange rate reflects the relative price of currencies, which are only used as units of account in the home and foreign markets. Prices are flexible, resulting in neutral monetary policy. The models are focused on the specification of the financial frictions that generate deviations from the UIP, and although they are highly stylized the resulting UIP conditions are robust to standard generalizations such as introducing production, labor market and investment, multiple goods and nominal rigidities.

The rest of the paper is organized as follows. Section 2 presents the GM and FS models alongside the simple portfolio adjustment cost model, adopted from SGU. Section 3 compares the log-linearized version of the models and derives the equivalence result. Section 4 concludes. 


\section{Three Models of Financial Frictions}

This section examines three modeling alternatives for generating deviations from the UIP: (1) the GM model, (2) the FS model, and (3) an ad-hoc portfolio adjustment cost as in SGU. Before getting into the different models, their common features are described below.

All models share the following basic structure. Consider a small open economy populated by a unit mass of households, a government and a financial sector. The economy is perfectly integrated in the world's goods market. There is one perishable good in the world economy and two currencies, home and foreign. Each period, households in the home economy are endowed with a random allocation of the good, $Y_{t}$. The households consume the good and trade it in the international markets. Consumption is denoted by $C_{t}$. The foreign currency price of the good is $P_{t}^{*}$. Assuming the law of one price holds, the domestic currency price of the good is $P_{t}=S_{t} P_{t}^{*}$, where $S_{t}$ is the nominal exchange rate (the price of foreign currency in terms of domestic currency). For simplicity assume $P_{t}^{*}=1$, suggesting $P_{t}=S_{t}$.

Foreign bonds pay a risk-free gross return of $R_{t}^{*}$. In steady state foreign return equals $\beta^{-1}$, where $0<\beta<1$ is the subjective discount factor of both domestic agents and foreigners. Foreign bonds are traded through the intermediation of the local financial sector. Domestic households own a fraction $\theta$ of the financial sector, where the rest is held by foreigners.

The central bank issues domestic risk-free nominal bonds, $B_{t}^{G}$, and controls their gross return, $R_{t}$. Only domestic agents hold domestic bonds. ${ }^{2}$ The households' holding of the bonds is denoted by $B_{t}^{H H}$, the rest is be held by the local financial sector. The consolidated government (monetary and fiscal authorities) budget constraint is given by:

$$
B_{t}^{G}=R_{t-1} B_{t-1}^{G}+T_{t}
$$

where $T_{t}$ is lump-sum transfers to the households.

\footnotetext{
${ }^{2}$ Introducing exogenous external demand for home bonds, i.e. capital inflow shocks, does not change
} the results below. 


\subsection{Model 1: The GM Model}

This section builds on Gabaix and Maggiori (2015). Households only hold domestic riskfree bonds, as they do not have access to the international financial markets. Financiers absorb domestic saving imbalances for a premium.

\subsubsection{Households}

The representative household solves:

$$
\begin{aligned}
\underset{\left.C_{t}, B_{t}^{H H}\right\}_{t=0}^{\infty}}{\operatorname{Max}} & E_{0} \sum_{t=0}^{\infty} \beta^{t} U\left(C_{t}\right) \\
\text { s.t. } & S_{t} C_{t}+B_{t}^{H H} \leq S_{t} Y_{t}+R_{t-1} B_{t-1}^{H H}+\theta S_{t} \Pi_{t}+T_{t}
\end{aligned}
$$

where $U(\cdot)$ is a concave and strictly increasing periodical utility function. $\Pi_{t}$ is the financiers' distributed dividends, denominated in foreign currency. The resulting Euler equation is given by:

$$
\begin{aligned}
U_{C, t} & =\beta R_{t} E_{t}\left(\frac{U_{C, t+1}}{\sigma_{t+1}}\right) \\
\text { where } \quad \sigma_{t+1} & \equiv \frac{S_{t+1}}{S_{t}}
\end{aligned}
$$

\subsubsection{Financiers}

Agents are selected at random to operate the financial firms for a single period. The selection process is memoryless. Financiers start each period with no liabilities and a net worth of $\overline{\mathcal{B}}$ (denominated in foreign currency), which is held in foreign bonds. They maintain this position through their dividend distribution policy. $\overline{\mathcal{B}}$ is interpreted as the financiers' preferred asset position, as they require a premium for deviating from it in order to absorb excess domestic savings. GM set $\overline{\mathcal{B}}$ to zero, but for sake of generality and comparability with the portfolio adjustment cost model, I relax their assumption. ${ }^{3}$ Note that since domestic households own a fraction $\theta$ of the financial firms, they only have a claim to $\theta \overline{\mathcal{B}}$ of their net worth. Let $\bar{b}$ denote that quantity, i.e. $\bar{b} \equiv \theta \overline{\mathcal{B}}$.

Let $Q_{t}$ denote the financiers' holdings of domestic bonds, which can be either positive or negative. The absolute value of $Q_{t}$ reflects the scale of financial intermediation in

${ }^{3}$ An alternative is to sacrifice generality by maintaining the GM parameterization and imposing zero steady-state net foreign asset position in the portfolio adjustment cost model. 
the economy. When domestic agents require excess resources, the financiers borrow from abroad in foreign currency and extend a loan of the same value in domestic currency to domestic agents $\left(Q_{t}>0\right)$. When domestic agents wish to save, they lend the financiers in domestic currency $\left(Q_{t}<0\right)$ and the financiers convert these funds into foreign bonds. Given the initial balance sheet of the financiers, they hold a net balance of $\mathcal{B}_{t}=\overline{\mathcal{B}}-\frac{Q_{t}}{S_{t}}$ of foreign bonds, regardless of whether $Q_{t}$ is positive or negative. Let $b_{t}$ denote the home agents claim on the base position plus the funds intermediated to foreign bonds, i.e. $b_{t}=\bar{b}-\frac{Q_{t}}{S_{t}}$. Notice that $b_{t}$ is the comparable quantity to the net foreign asset position in the portfolio adjustment cost model presented below, as it measures in both models the long run exposure of domestic agents to foreign assets plus their excess savings.

The financiers' pre-dividend domestic-currency value at the end of their one period term is given by $R_{t} Q_{t}+S_{t+1} R_{t}^{*} \mathcal{B}_{t}$, and they seek to maximize its expected discounted value, which can be written as:

$$
V_{t}=\left[1-\frac{R_{t}^{*}}{R_{t}} E_{t}\left(\sigma_{t+1}\right)\right] Q_{t}+E_{t}\left(S_{t+1}\right) \frac{R_{t}^{*}}{R_{t}} \overline{\mathcal{B}}
$$

Financiers are unable to perfectly commit to repay their creditors, and before the end of period $t$, i.e. before $S_{t+1}$ is realized, they can divert a portion $\Gamma\left|\frac{Q_{t}}{S_{t}}\right|$ of their liabilities. GM assume that $\Gamma>0$ is an increasing function of the variance of the exchange rate, which captures a limited capacity to take risk. They note that this assumption reflects the idea that the financiers' outside options are increasing in the size and volatility, or complexity, of their balance sheet.

Since creditors correctly anticipate the incentives of the financiers, the latter are subject to a credit constraint of the form:

$$
V_{t} \geq E_{t}\left(S_{t+1}\right) \frac{R_{t}^{*}}{R_{t}} \overline{\mathcal{B}}+\Gamma\left|\frac{Q_{t}}{S_{t}}\right|\left|Q_{t}\right|=E_{t}\left(S_{t+1}\right) \frac{R_{t}^{*}}{R_{t}} \overline{\mathcal{B}}+\Gamma \frac{Q_{t}^{2}}{S_{t}}
$$

The financiers' problem is therefore to choose $Q_{t}$ so as to maximize $V_{t}$, as presented in (3), subject to (4). Since the objective function is linear in $Q_{t}$ while the constraint is convex, at the optimum the constraint always binds, and after using $-\frac{Q_{t}}{S_{t}}=\mathcal{B}_{t}-\overline{\mathcal{B}}$, the financiers' demand for foreign assets is given by:

$$
\mathcal{B}_{t}=\overline{\mathcal{B}}+\frac{1}{\Gamma}\left[\frac{R_{t}^{*}}{R_{t}} E_{t}\left(\sigma_{t+1}\right)-1\right]
$$


As $\Gamma \rightarrow 0$ the UIP holds, i.e. $E_{t}\left(\sigma_{t+1}\right) \rightarrow \frac{R_{t}}{R_{t}^{*}}$, and the financiers can bear any exposure to foreign assets. On the other hand, when $\Gamma \rightarrow \infty$, they do not deviate from their preferred position, and the economy is essentially in financial autarky as households cannot use the international financial markets to absorb excess domestic savings.

Using $\mathcal{B}_{t}-\overline{\mathcal{B}}=b_{t}-\bar{b}$, and rearranging the condition above gives the modified UIP:

$$
E_{t}\left(\sigma_{t+1}\right)=\frac{R_{t}}{R_{t}^{*}}\left[1+\Gamma\left(b_{t}-\bar{b}\right)\right]
$$

Finally, for completeness, the financiers' distributed dividends are given by:

$$
\Pi_{t}=\left(R_{t-1}^{*}-\frac{R_{t-1}}{\sigma_{t}}\right)\left(\mathcal{B}_{t-1}-\overline{\mathcal{B}}\right)+\left(R_{t-1}^{*}-1\right) \overline{\mathcal{B}}
$$

\subsubsection{Market Clearing and the BOP}

Market clearing in the financial markets dictates:

$$
B_{t}^{H H}+Q_{t}=B_{t}^{G}
$$

The balance of payments (BOP) identity is derived by consolidating the government budget constraint, the households' budget constraint and financiers' dividends together with the market clearing condition above. After using the relation between $\mathcal{B}_{t}$ and $b_{t}$, $\mathcal{B}_{t}=b_{t}+(1-\theta) \overline{\mathcal{B}}$ and $\bar{b}=\theta \overline{\mathcal{B}}$, the BOP identity reads:

$$
\begin{aligned}
b_{t}-b_{t-1}= & Y_{t}-C_{t} \\
& -(1-\theta)\left(R_{t-1}^{*}-\frac{R_{t-1}}{\sigma_{t}}\right)\left(b_{t-1}-\bar{b}\right) \\
& +\left(R_{t-1}^{*}-1\right) b_{t-1}
\end{aligned}
$$

The left-hand side is the financial account, which equals the change in the net foreign asset position of home agents. The right-hand side is the current account, which equals net exports (first line), minus dividend payment to foreigners against their intermediation services (second line), plus interest income from abroad (third line).

\subsubsection{Closing the Model}

The Euler condition, equation (2), the modified UIP, equation (5), and the BOP, equation (6), result in a system of 3 equations in 4 endogenous variables: $C_{t}, R_{t}, \sigma_{t}$, and $b_{t} . Y_{t}$ and $R_{t}^{*}$ are exogenous. The model is closed by specifying a policy rule for the nominal interest rate, $R_{t}$. 


\subsection{Model 2: The FS Model}

This section builds on Fanelli and Straub (2019). The households' problem in this model is identical to that of GM, so I start with the description of the financiers.

\subsubsection{Financiers}

A unit mass of financial firms intermediate between domestic households and the international financial markets. Financial firms face two restrictions: (1) net intermediated funds by each firm cannot exceed some regulatory limit $X$, measured in foreign currency; and (2) firms face idiosyncratic participation cost in the international financial markets, similar to the mechanism of Alvarez, Atkeson and Kehoe (2009). In particular, firm $f$ faces a cost of $\gamma(f)$ percent of its intermediated funds, where $\gamma(0)=0$ and $\gamma(f)$ is continuously differentiable with $\gamma^{\prime}(f)>0$.

Each period financiers distribute dividends to their shareholders after incurring the periodical participation cost. ${ }^{4}$ Their dividend distribution policy is to maintain their net worth at $\overline{\mathcal{B}}$, where $\overline{\mathcal{B}}$ is measured in foreign currency and is held in foreign bonds. Let $\bar{b} \equiv \theta \overline{\mathcal{B}}$ denote the claim of domestic agents on the financiers' base position. In FS, $\overline{\mathcal{B}}$ is zero, but again, for sake of generality and comparability with the portfolio adjustment cost model, a non-zero value is allowed.

Let $Q_{f t}$ denote firm $f$ holdings of domestic bonds, which can be either positive or negative. Given the dividend distribution policy, financier $f$ holds $\mathcal{B}_{f t}=\overline{\mathcal{B}}-\frac{Q_{f t}}{S_{t}}$ units of foreign bonds. Let $b_{f t}$ denote the home agents claim on the base position of firm $f$ plus the funds it intermediates to foreign bonds, i.e. $b_{f t}=\bar{b}-\frac{Q_{f t}}{S_{t}}$.

Intermediary $f$ optimally invests an amount $Q_{f t}$ by maximizing the expected discounted value of its portfolio subject to the regulatory constraint:

$$
\underset{-\frac{Q_{f t}}{S_{t}} \in[-X,+X]}{\operatorname{Max}} \quad\left[1-\frac{R_{t}^{*}}{R_{t}} E_{t}\left(\sigma_{t+1}\right)\right] Q_{f t}+E_{t}\left(S_{t+1}\right) \frac{R_{t}^{*}}{R_{t}} \overline{\mathcal{B}}-\gamma(f)\left|Q_{f t}\right|
$$

\footnotetext{
${ }^{4}$ FS write their model in continuous time, thereby avoiding the need to address the timing of dividend payments. The assumption in the text, that dividends are paid after incurring the periodical participation cost, results in formulation similar to FS. Assuming alternatively, that dividends are distributed before incurring the cost, does not affect the results of this paper but makes the algebra a bit more cumbersome. The derivation of the model under the alternative timing convention is available from the author upon request.
} 
Since the objective function is linear in $Q_{f t}$, participating firms will take a foreign position up to the limit of their regulatory constraint.

Participation is determined by comparing the marginal benefit of investing in the foreign financial markets, $\left|\frac{R_{t}^{*}}{R_{t}} E_{t}\left(\sigma_{t+1}\right)-1\right|$, to the marginal cost, $\gamma(f)$. Firm $f$ policy rule is thus:

$$
\begin{aligned}
-\frac{Q_{f t}}{S_{t}} & = \begin{cases}X \cdot \operatorname{sign}\left(\tau_{t}\right) & \text { if } \gamma(f) \leq\left|\tau_{t}\right| \\
0 & \text { Otherwise }\end{cases} \\
\text { where } \quad \tau_{t} & \equiv \frac{R_{t}^{*}}{R_{t}} E_{t}\left(\sigma_{t+1}\right)-1
\end{aligned}
$$

That is, intermediary $f$ will "go long" on foreign bonds up to the regulatory limit $X$ if $R_{t}^{*} E_{t}\left(\sigma_{t+1}\right)>R_{t}$ and will "go short" up to $-X$ if $R_{t}^{*} E_{t}\left(\sigma_{t+1}\right)<R_{t}$, provided that the expected excess return is larger than its marginal cost $\gamma(f)$. Firms with higher marginal cost do not deviate from their initial foreign position $\overline{\mathcal{B}}$. The marginal active financier, $\bar{f}_{t}$, satisfies:

$$
\gamma\left(\bar{f}_{t}\right)=\left|\tau_{t}\right| \quad \Rightarrow \quad \bar{f}_{t}=\gamma^{-1}\left(\left|\tau_{t}\right|\right)
$$

Integrating the policy rule over all firms, using $b_{t}-\bar{b}=-\int_{0}^{1} \frac{Q_{f t}}{S_{t}} d f=-\frac{Q_{t}}{S_{t}}$, and substituting for $\bar{f}_{t}$, gives:

$$
b_{t}-\bar{b}=\gamma^{-1}\left(\left|\tau_{t}\right|\right) X \cdot \operatorname{sign}\left(\tau_{t}\right)
$$

which is the modified UIP in this model. Notice that as $X \rightarrow 0$ firms have no access the foreign financial markets, $\left|Q_{t}\right| \rightarrow 0$, and the economy is effectively in financial autarky. With no regulatory limits, i.e. as $X \rightarrow \infty$, financiers want to take infinite foreign position for any non-zero expected excess return in the currency market, driving $\tau_{t}$ to zero and the UIP holds.

To illustrate the similarity of this model to the GM model, consider the special case where $\gamma(f)=a f$. In this case $\bar{f}_{t}=\frac{1}{a}\left|\tau_{t}\right|$, and noting that $\tau_{t}=\left|\tau_{t}\right| \cdot \operatorname{sign}\left(\tau_{t}\right)$, equation (7) suggests:

$$
E_{t}\left(\sigma_{t+1}\right)=\frac{R_{t}}{R_{t}^{*}}\left[1+\frac{a}{X}\left(b_{t}-\bar{b}\right)\right]
$$

Recalling equation (5), this case is therefore identical to the GM model with $\Gamma=a / X$. In the GM model foreign asset positions are constrained by the ability of financiers to absorb 
risk, while here they are constrained by regulation and participation cost. We will see that for a general $\gamma(\cdot)$ equations (5) and (7) turn identical at first-order approximation. ${ }^{5}$

Finally, for completeness, the financiers' aggregate distributed dividends are given by:

$$
\begin{aligned}
\Pi_{t} & =\left(R_{t-1}^{*}-\frac{R_{t-1}}{\sigma_{t}}\right)\left(\mathcal{B}_{t-1}-\overline{\mathcal{B}}\right)+\left(R_{t-1}^{*}-1\right) \overline{\mathcal{B}}-X \Gamma\left(\tau_{t}\right) \\
\text { where } \quad \Gamma\left(\tau_{t}\right) & \equiv \int_{0}^{\bar{f}_{t}=\gamma^{-1}\left(\left|\tau_{t}\right|\right)} \gamma(f) d f \quad, \quad \mathcal{B}_{t} \equiv \int_{0}^{1} \mathcal{B}_{f t} d f
\end{aligned}
$$

Note that $\Pi_{t}$ depends on revenue from the portfolio of the previous period, net of current period participation cost. This reflects the assumption that the profits from the portfolio of the previous period are distributed, so as to maintain a net worth of $\overline{\mathcal{B}}$, after incurring the current period participation cost.

\subsubsection{Market Clearing and the BOP}

In the financial markets:

$$
B_{t}^{H H}+Q_{t}=B_{t}^{G}
$$

The BOP identity is derived by consolidating the government budget constraint, the households' budget constraint and financiers' distributed dividends together with the market clearing condition above. The BOP identity in this model reads:

$$
\begin{aligned}
b_{t}-b_{t-1}= & Y_{t}-C_{t}-\theta X \Gamma\left(\tau_{t}\right) \\
& -(1-\theta)\left(R_{t-1}^{*}-\frac{R_{t-1}}{\sigma_{t}}\right)\left(b_{t-1}-\bar{b}\right) \\
& +\left(R_{t-1}^{*}-1\right) b_{t-1}
\end{aligned}
$$

This is identical to the BOP under the GM model, equation (6), with the exception of the presence of the share of the domestic economy in the aggregate participation cost, $\theta X \Gamma\left(\tau_{t}\right)$, as it represents a loss of real resources. Note however, that in steady state its value and the value of its first derivative are zero, and hence it drops out of the linearized version of the model. ${ }^{6}$

\footnotetext{
${ }^{5}$ Panel A in Table 1 presents equation (7) in log-linearized form. Note that the sign of $b_{t}-\bar{b}$ in the approximated equation is determined by the sign of $\widetilde{R}_{t}^{*}-\widetilde{R}_{t}+E_{t}\left(\widetilde{\sigma}_{t+1}\right)$. The details of the derivation are presented in the appendix.

${ }^{6}$ See details in the appendix.
} 


\subsubsection{Closing the Model}

Recall that the households' problem is identical to the one in the GM model and hence the Euler condition, equation (2), holds in the FS model as well. This, together with the modified UIP, equation (7), and the BOP, equation (8), results in a system of 3 equations in 4 endogenous variables: $C_{t}, R_{t}, \sigma_{t}$, and $b_{t}$. $Y_{t}$ and $R_{t}^{*}$ are exogenous. The model is closed by specifying a policy rule for the nominal interest rate, $R_{t}$.

\subsection{Model 3: Portfolio Adjustment Cost}

In this version, domestic households have access to the international financial markets, but they face a convex adjustment cost whenever the level of their foreign asset position deviates from some long run target level, $\bar{b}$, as in "model 3" of Schmitt-Grohé and Uribe (2003). These costs may represent the cost of financial services, and I assume that a fraction $\theta$ of the cost is rebated to the households.

\subsubsection{Households}

In this version the representative household solves:

$$
\begin{aligned}
& \underset{\left\{C_{t}, B_{t}^{H H}, b_{t}\right\}_{t=0}^{\infty}}{\operatorname{Max}} \quad E_{0} \sum_{t=0}^{\infty} \beta^{t} U\left(C_{t}\right) \\
& \text { s.t. } \\
& S_{t} C_{t}+B_{t}^{H H}+S_{t} b_{t}+S_{t} \psi\left(b_{t}-\bar{b}\right) \leq S_{t} Y_{t}+R_{t-1} B_{t-1}^{H H}+S_{t} R_{t-1}^{*} b_{t-1}+\theta S_{t} \Pi_{t}+T_{t}
\end{aligned}
$$

where $b_{t}$ denotes the households' net holding of foreign bonds, and $\psi(\cdot)$ is a convex cost function (expressed in foreign currency) that satisfies:

$$
\psi(\cdot) \geq 0 \quad, \quad \psi(0)=0 \quad, \quad \psi^{\prime}(0)=0 \quad, \quad \psi^{\prime \prime}(\cdot)>0
$$

$\Pi_{t}$ is the average adjustment cost in the economy and each household is rebated a portion $\theta$ of that cost. Since the rebate is a function of the economy's average cost, households do not internalize the effect of their choice of $b_{t}$ on $\Pi_{t}$.

The households' optimality conditions are given by:

$$
\begin{aligned}
U_{C, t} & =\beta R_{t} E_{t}\left(\frac{U_{C, t+1}}{\sigma_{t+1}}\right) \\
U_{C, t}\left[1+\psi^{\prime}\left(b_{t}-\bar{b}\right)\right] & =\beta R_{t}^{*} E_{t}\left(U_{C, t+1}\right)
\end{aligned}
$$


Combining the two equations together gives the modified UIP:

$$
R_{t} E_{t}\left(\frac{U_{C, t+1}}{\sigma_{t+1}}\right)\left[1+\psi^{\prime}\left(b_{t}-\bar{b}\right)\right]=R_{t}^{*} E_{t}\left(U_{C, t+1}\right)
$$

\subsubsection{Market Clearing and BOP}

In the financial markets:

$$
B_{t}^{H H}=B_{t}^{G}
$$

The BOP identity is derived by consolidating the government budget constraint and the households' budget constraint, while taking account that a portion $\theta$ of the portfolio adjustment cost is rebated to the households. The BOP equation reads:

$$
b_{t}=Y_{t}-C_{t}+R_{t-1}^{*} b_{t-1}-(1-\theta) \psi\left(b_{t}-\bar{b}\right)
$$

\subsubsection{Closing the Model}

The households' optimality conditions, equations (9) and (11), together with the BOP, equation (12), result in a system of 3 equations in 4 endogenous variables: $C_{t}, R_{t}, \sigma_{t}$, and $b_{t}$. $Y_{t}$ and $R_{t}^{*}$ are exogenous. The model is closed by specifying a policy rule for the nominal interest rate, $R_{t}$.

\section{Model Comparison}

This section compares the models. The households' Euler equation is identical across models, see equations (2), and (9), while recall that (2) is common to both GM and FS models. I will therefore only compare the modified UIP equations and the BOP identities.

\subsection{First-Order UIP Equivalence}

Panel A of Table 1 presents the modified UIP equation of each model after log-linearization, equations (5), (7) and (11). In all models the deviation of the net foreign assets position from its steady state, $b_{t}-\bar{b}$, drives a wedge between the expected depreciation of the domestic currency and the economy's interest rate differential against the rest of the world. The UIP relations may only differ in the coefficient multiplying $b_{t}-\bar{b}$, hence giving rise to the following result. 
Table 1: First-Order Approximation of the UIP and BOP Equations*

\section{Panel A: The Modified UIP}

$\begin{array}{lll}\text { The GM Model: } & E_{t}\left(\widetilde{\sigma}_{t+1}\right) \cong \widetilde{R}_{t}-\widetilde{R}_{t}^{*}+\Gamma\left(b_{t}-\bar{b}\right) & \Gamma>0 \\ \text { The FS Model: } & E_{t}\left(\widetilde{\sigma}_{t+1}\right) \cong \widetilde{R}_{t}-\widetilde{R}_{t}^{*}+\frac{\gamma^{\prime}(0)}{X}\left(b_{t}-\bar{b}\right) & \frac{\gamma^{\prime}(0)}{X}>0 \\ \text { Portfolio Adj. Cost: } & E_{t}\left(\widetilde{\sigma}_{t+1}\right) \cong \widetilde{R}_{t}-\widetilde{R}_{t}^{*}+\psi^{\prime \prime}(0)\left(b_{t}-\bar{b}\right) & \psi^{\prime \prime}(0)>0\end{array}$

\section{Panel B: The BOP Identity}

In all Models:

$$
\begin{aligned}
& b_{t}-\bar{b} \cong Y_{s s} \widetilde{Y}_{t}-C_{s s} \widetilde{C}_{t}+\frac{1}{\beta} \bar{b} \widetilde{R}_{t-1}^{*}+\frac{1}{\beta}\left(b_{t-1}-\bar{b}\right) \\
& \text { where } C_{s s}=Y_{s s}+\left(\beta^{-1}-1\right) \bar{b}
\end{aligned}
$$

* Tilde variables denote $\log$-deviations from the deterministic steady state, i.e. $\widetilde{X}_{t} \equiv \log \left(\frac{X_{t}}{X_{s s}}\right)$.

Result 1 (UIP Equivalence) If models are calibrated such that $\Gamma=\frac{\gamma^{\prime}(0)}{X}=\psi^{\prime \prime}(0)$ then, to a first-order approximation, they all generate identical UIP equations.

Gabaix and Maggiori (2015) have forcefully demonstrated that their theory can help rationalize the empirical behavior of exchange rates, and provide a solution for the exchange rate disconnect and the forward premium puzzles. Fanelli and Straub (2019) use their model to lay down important principles for FXI policy. Both theories are centered around the imperfections in the financial markets, as described above, and the wedge they create in the UIP condition. In these models deviations from the long-run foreign asset position are associated with excess expected return in one of the currencies. It therefore comes at no surprise to find that the UIP relation implied by these theories is closely related to that of the ad-hoc portfolio adjustment cost model, as the latter simply assume that excess returns are driven by movement in the foreign asset position.

When the coefficients governing the financial frictions do not enter differentially into the models, as is the case here, it is impossible to distinguish between the underlying 
mechanisms generating the deviation from the UIP. Potentially, one could attempt calibrating the models using outside information regarding risk attitude $(\Gamma)$ or financial intermediation cost $\left(\gamma^{\prime}\right.$ and $\left.\psi^{\prime \prime}\right)$, but these would be unrelated to the moments generated by the models. Standard calibration procedures that attempt to bring some second moments in the model close to their parallels in the data, would bring the coefficients across models close to each other as required by Result 1. In that case the simple modeling strategy is robust to different micro foundations, and there is no gain from committing to a specific microstructure. The ad-hoc modeling strategy is just as good, at least to first order.

Nevertheless, several authors have emphasized the importance of higher order approximation of DSGE models, cautioning against the implications of using linearized models, e.g. Fernández-Villaverde et-al (2006), Amisano and Tristani (2010) and Lindé and Trabandt (2019). It is therefore interesting to take a peek at what is dropped out when one settles for a first-order approximation. To that end, compare the excess foreign returns in the GM and SGU models, as suggested by equations (5) and (11): ${ }^{7}$

$$
\frac{R_{t}^{*}}{R_{t}} E_{t}\left(\sigma_{t+1}\right)= \begin{cases}1+\Gamma\left(b_{t}-\bar{b}\right) & \text { GM model } \\ E_{t}\left(\frac{U_{C, t+1}}{\sigma_{t+1}}\right) \frac{E_{t}\left(\sigma_{t+1}\right)}{E_{t}\left(U_{C, t+1}\right)}\left[1+\psi^{\prime}\left(b_{t}-\bar{b}\right)\right] & \text { Portfolio adjustment cost }\end{cases}
$$

Note that the premium in the GM model is linear in $b_{t}$, suggesting that a first-order approximation does not neglect any higher order terms that are generated by the financial friction. In contrast, under the portfolio adjustment cost model, there are two sources of higher order fluctuations: (1) the standard risk premium as captured by the covariance of the marginal utility of consumption with the exchange rate (the Jensen's inequality term in front of the square brackets); and (2) the ad-hoc specification of the adjustment cost function. If the cost function is quadratic, then the premium is linear in $b_{t}$ as in the GM model. This comparison suggests that any higher order differences emerging from the modified UIPs are driven by nonlinearities of the adjustment cost model, rather than

\footnotetext{
${ }^{7}$ Recall that with a linear participation cost the FS model generates identical UIP equation as the GM model, hence the comparison below holds for the FS model as well. Clearly, under a nonlinear specification for the participation cost, the FS model would generate higher order terms, but these would be as ad-hoc as the specification of the adjustment cost in SGU.
} 
by missing important micro-founded dynamics captured by the GM model. ${ }^{8}$ This result also works in favor of adopting the simple adjustment cost model.

\subsection{First-Order BOP Equivalence}

Panel B of Table 1 presents the approximated BOP identities of the models, equations (6), (8) and (12).

Result 2 (BOP Equivalence) To a first order-approximation, all models generate identical BOP equations.

Observing the BOP equations in exact form, before the approximation, it is clear that they only differ in costs and dividends. However, these are second order. In particular, the dividends from intermediation activity in the GM and FS models rely on the interaction between differentials in returns on foreign and home bonds, $R_{t-1}^{*}-\frac{R_{t-1}}{\sigma_{t}}$, and the deviation of the foreign asset position from its long run level, $b_{t-1}-\bar{b}$. Both are zero in steady state, and therefore are washed away in the approximation. As for the costs, the portfolio adjustment cost in SGU is second order simply by assuming $\psi(0)=\psi^{\prime}(0)=0$, and the details of the derivation for the participation cost in the FS model are presented in the appendix.

\section{Conclusion}

This paper has demonstrated that, to a first-order approximation, the micro-founded models of GM and FS are equivalent to the simple reduced-form portfolio adjustment cost model of SGU.

Importantly, the GM and FS models are centered around the micro structure that generates deviations from the UIP condition; however, to a first order approximation, these end up identical to the deviations generated by a reduced-form portfolio adjustment cost friction. Specifically, in all models the linearized deviation is proportional to the distance of the net foreign asset position of the economy from its long-run level. The underlying mechanism driving this result is different across models. In GM, financiers

\footnotetext{
${ }^{8}$ Or by the FS model - see the previous footnote.
} 
are willing to absorb saving imbalances for a premium, and in FS financial intermediation is associated with participation cost which, in turn, drives a wedge between domestic and foreign returns. As a result, in both models movement in the foreign asset position is accompanied by movement in the effective return on foreign assets faced by domestic agents. The reduced-form portfolio adjustment cost model generates this result simply by assumption. It therefore should come as no surprise to find that the deviations from the UIP in all models are closely related.

The implication of the equivalence result is that, to the extent that the economic analysis is focused on first-order dynamics and second moments - as is typically the case in the open economy business cycle literature and in many new-Keynesian contributions there is no gain from adopting the rich micro-structure of either GM or FS, as the simple and ad-hoc adjustment cost friction is robust to different underlying micro interpretations.

Moreover, the paper has also shown that higher order differences in the UIP wedge are driven by nonlinearities in the adjustment cost model, rather than by missing important micro-founded dynamics captured by the GM or FS models.

In sum, it seems that adopting the simple modeling strategy of the adjustment cost model comes with no cost in many economic applications, at least compared with the two alternatives considered in this paper.

\section{A Technical Appendix}

This appendix provides details on the derivation of the log-linearized equations under the FS model.

Recall the modified UIP equation under the FS model, equation (7). In order to avoid the absolute value and the sign operator, this equation can be written as:

$$
\begin{aligned}
b_{t}-\bar{b} & =\gamma^{-1}\left(\left|\tau_{t}\right|\right) X \cdot \operatorname{sign}\left(\tau_{t}\right)= \begin{cases}\gamma^{-1}\left(\tau_{t}\right) X & \text { for } \tau_{t} \geq 0 \\
-\gamma^{-1}\left(-\tau_{t}\right) X & \text { for } \tau_{t}<0\end{cases} \\
\text { where } \quad \tau_{t} & \equiv \frac{R_{t}^{*}}{R_{t}} E_{t}\left(\sigma_{t+1}\right)-1
\end{aligned}
$$

Notice that for $\tau \geq 0$ :

$$
\frac{\partial \gamma^{-1}\left(\tau_{t}\right)}{\partial \tau_{t}}=\frac{1}{\gamma^{\prime}\left(\gamma^{-1}\left(\tau_{t}\right)\right)}
$$


and for $\tau<0$ :

$$
\frac{\partial-\gamma^{-1}\left(-\tau_{t}\right)}{\partial \tau_{t}}=\frac{1}{\gamma^{\prime}\left(\gamma^{-1}\left(-\tau_{t}\right)\right)}
$$

Suggesting that at the steady state, i.e. at $\tau_{s s}=0$, the derivative of the expression on the right hand side of (A.1) is continuous at zero and equals $\frac{X}{\gamma^{\prime}(0)}$. Therefore, a first order approximation of (A.1) results in:

$$
b_{t}-\bar{b} \cong \frac{1}{\gamma^{\prime}(0)} X \tau_{t}
$$

Using the definition of $\tau_{t}$ to substitute for its first-order approximation gives:

$$
E_{t}\left(\widetilde{\sigma}_{t+1}\right) \cong \widetilde{R}_{t}-\widetilde{R}_{t}^{*}+\frac{\gamma^{\prime}(0)}{X}\left(b_{t}-\bar{b}\right)
$$

where tilde variables to denote log-deviations from steady state. Equation (A.2) is the second equation on Panel A of Table 1.

As for the BOP equation, equation (8), I only note that the aggregate participation cost, $X \Gamma\left(\tau_{t}\right)$, drops out under first order approximation. Recall that $\Gamma\left(\tau_{t}\right) \equiv$ $\int_{0}^{\bar{f}_{t}=\gamma^{-1}\left(\left|\tau_{t}\right|\right)} \gamma(f) d f$; hence, using the Leibniz rule:

$$
\frac{\partial \Gamma}{\partial \tau_{t}}\left(\tau_{t}\right)=\gamma\left(\gamma^{-1}\left(\left|\tau_{t}\right|\right)\right) \frac{\partial \gamma^{-1}\left(\left|\tau_{t}\right|\right)}{\partial\left|\tau_{t}\right|} \operatorname{sign}\left(\tau_{t}\right)=\frac{\left|\tau_{t}\right| \operatorname{sign}\left(\tau_{t}\right)}{\gamma^{\prime}\left(\gamma^{-1}\left(\left|\tau_{t}\right|\right)\right)}=\frac{\tau_{t}}{\gamma^{\prime}\left(\gamma^{-1}\left(\left|\tau_{t}\right|\right)\right)}
$$

and since $\tau_{s s}=0$, the term $X \Gamma\left(\tau_{t}\right)$ is zeroed out under a first order approximation, as suggested by Panel B of Table 1.

\section{References}

[1] Alla, Z., Espinoza, R. A., Gosh, A. R., 2017. "FX Intervention in the New Keynesian Model." International Monetary Fund Working Paper WP/17/207.

[2] Alvarez, F., Atkeson, A., Kehoe, P. J., 2009. "Time-Varying Risk, Interest Rates, and Exchange Rates in General Equilibrium." The Review of Economic Studies 76(3), pp. $851-878$.

[3] Amisano, G., Tristani, O., 2010. "Euro Area Inflation Persistence in An Estimated Nonlinear DSGE Model." Journal of Economic Dynamics and Control 34(10), pp. $1837-1858$. 
[4] Backus, D. K., Kehoe, P. J., 1989. "On the Denomination of Government Debt: A Critique of the Portfolio Balance Approach." Journal of Monetary Economics 23(3), pp. 359-376.

[5] Benes, J., Berg, A., Portillo, R. A., Vavra, D., 2015. "Modeling Sterilized Interventions and Balance Sheet Effects of Monetary Policy in a New-Keynesian Framework." Open Economy Review 26(1), pp. 81-108.

[6] Cavallino, P., 2019. "Capital Flows and Foreign Exchange Intervention." American Economic Journal: Macroeconomics 11(2), pp. 127-170.

[7] Engel, C., 2014. "Exchange Rates and Interest Parity." In: Handbook of International Economics, Vol. 4, edited by Gita Gopinath and Elhanan Helpman, pp. 453-522. Elsevier.

[8] Fanelli, S., Straub, L., 2018. "A Theory of Foreign Exchange Interventions." 2018 Meeting Papers 1270, Society for Economic Dynamics.

[9] Fernández-Villaverde, J., Rubio-Ramírez, J. F., Santos, M. S., 2006. "Convergence Properties of the Likelihood of Computed Dynamic Models." Econometrica 74(1), pp. 93-119.

[10] Gabaix, X., Maggiori, M., 2015. "International Liquidity and Exchange Rate Dynamics." The Quarterly Journal of Economics 130(3), pp. 1369-1420.

[11] Lindé, J., Trabandt, M., 2019. "Resolving the Missing Deflation Puzzle." CEPR Discussion Papers 13690.

[12] Schmitt-Grohé, S., Uribe, M., 2003. "Closing Small Open Economy Models." Journal of International Economics 61(1), pp. 163-185. 